\title{
A Study on Exploration of Ethnobotanical Knowledge of Rural Community in Bangladesh: Basis for Biodiversity Conservation
}

\author{
Md. Habibur Rahman \\ Bangladesh Institute of Social Research (BISR), Hasina De Palace, House No. 6/14, Block No. A, Lalmatia, Dhaka 1207, Bangladesh \\ Correspondence should be addressed to Md. Habibur Rahman; habibmdr@gmail.com
}

Received 23 April 2013; Accepted 6 June 2013

Academic Editors: A. R. Atangana, M. Tigabu, and J. Zhang

Copyright ( 2013 Md. Habibur Rahman. This is an open access article distributed under the Creative Commons Attribution License, which permits unrestricted use, distribution, and reproduction in any medium, provided the original work is properly cited.

Rural home garden is an important traditional source of medicinal plants for daily curative uses throughout Bangladesh. Such knowledge is continuing from generation to generation without documentation. An ethnobotanical investigation was conducted through focus group discussions and households' survey accompanied by field observation to document the indigenous knowledge of herbal medicines being used by the rural communities of Comilla district in Bangladesh. A total of 45 ethnomedicinal plant species belonging to 34 families were found, where trees (37.78\%) were the most commonly utilized growth form. Plant resources are used to treat 31 different individual ailments ranging from simple cuts to heart disease. Plants are mainly used to treat dysentery (12 species), cold ailments, cough, and fever (6 species each). For curing ailments, the use of the above ground plant parts was higher (86.44\%); particularly fruits (37.29\%) and leaves (30.51\%) were the most commonly used plant parts. More than half of the medicinal plants are indigenous (71.11\%), being edible fruit bearer (48.89\%), plants parts suitable for animals and birds (57.78\%), and natural regeneration present (64.44\%) indicated that medicinal plants play a vital role in biodiversity conservation in the study area.

\section{Introduction}

Over the past decade, there has been a dramatic increase in the demand for medicinal plants for use in traditional medicine and contemporary and alternative medicine in both developing and developed countries [1]; thus, a large number of people habitually use such medication because herbal treatment is, in some cases, considered relatively cheap [2]. However, its popularity also stems from the efficacy of the treatment in most cases and relative safety, with few or no side effects. Herbal medicines, because of their decentralized nature, are generally easily and quickly available [3]. Now, both developed and developing countries are involved in plants-based herbal medicine system, as modern pharmaceuticals are not accessible for all [4].

Bangladesh is a country that is considered rich in medicinal plants genetic resources by virtue of its favorable agroclimatic condition and seasonal diversity. With productive soils, a tropical climate, and seasonal diversity, Bangladesh contains about 6500 plants species including bryophytes, pteridophytes, gymnosperms, and angiosperms; among them, 500 plant species have medicinal values [5] and grow in the country's forests, wetlands, homestead forests, and even roadside as indigenous, naturally occurring, or cultivated plants [6, 7]. About 75\% (10 million households in over 85,000 villages) of the country's total population lives in rural areas [8], and almost $80 \%$ is dependent on natural resources (e.g., medicinal plants) for their primary healthcare [9], with herbal medication remaining a popular and accepted form of treatment [10].

Rural peoples are capable to identify many species of plants that are capable of producing various products, including food, firewood, medicine, forage, and daily needs tools [11], and the customary homestead tree production system also serves as a source of plant products and remedies [12]. Despite such a high demand of herbal medicine, medicinal plants sector is now the most promising business sector in Bangladesh [13] with the presence of more than 500 companies producing herbal medicines [14], and more than $90 \%$ of the plants and products needed to meet domestic demand 
are imported from other countries, such as India, Nepal, and Pakistan [15].

The indigenous knowledge (IK) (IK develops through sharing experience and is normally passed orally between generations) concerning medicinal plants is lost owing to the change of habitats and culture of rural communities in Bangladesh. The district of Comilla is situated in the eastern part of Bangladesh, a district devoid of natural forests (out of the 64 districts of Bangladesh, 28 districts do not have any natural forests). Rajendrapur Sal forest (Shorea robusta C.F. Gaertn) and degraded small Sal patches in Kotbari and Lalmai hills are most notable because these were the only planted forests in the district, and Sal forest and Lalmai hills have historical importance. The district was chosen because it is a transitional zone between the southeastern vast hilly region (i.e., Chittagong Hill Tracts) and other plains regions in the southern and middle of the country. Although there are no significant forest areas, there is a great diversity of medicinal plants in the homestead gardens, roadsides, pond banks, and graveyards in this region. In conjunction with the increasing demand for traditional medicines in the country, research is being conducted outside the forest areas to explore the ethnobotanical documentation of the medicinal plants; for example, $[9,12,16-27]$ are common to mention, but no study has been found on the utilization of plants for healthcare practices by the rural people in Comilla district of the country. Therefore, the study was undertaken in Burichong Upazila (subdistrict, an administrative entity) of Comilla district of Eastern Bangladesh. Its aim was to assess plantbased ethnomedicinal practice and document IK associated with it, traditional beliefs, and biodiversity conservation related to IK.

\section{Materials and Methods}

2.1. Study Area. Burichong Upazila with an area of $163.76 \mathrm{sq}$. $\mathrm{km}$. is located at $23^{\circ} 55^{\prime} 00^{\prime \prime} \mathrm{N} 91^{\circ} 12^{\prime} 64^{\prime \prime} \mathrm{E}$ (Figure 1). This area is bounded by Brahmanpara Upazila on the north, Comilla Sadar and Barura Upazilas on the south, Tripura state of India on the east, and Debidwar and Chandina Upazilas on the west. It has 37739 units of households. The Upazila supports a population of 259,265; 133,469 male and 125,796 female (population density 1609.98 per sq. km.) with a literacy rate of $49.7 \%$. The Upazila consists of 8 Union Parishads (last stage of administrative entity) and 171 villages. The main rivers are Gomti, Gongur, Titi, and Pagli rivers; the landscape comprises the Tripura valley of India and green agricultural fields. The Upazila is more or less flooded during the rainy season, resulting in deposition of sediments that increase the productivity of land, ultimately contributing to its botanical diversity. The main occupation is agriculture (56.64\%), followed by agricultural labour (12.28\%), commerce (10.23\%), service (8.08\%), and so forth [28]. However, Burichong Upazila is considered as one of the most densely homestead forests-covered area with plantations of both indigenous and exotic species and understory covered with rich herbs and shrubs.
2.2. Research Methods. In order to document the utilization of medicinal plants, four field surveys were carried out from early July to late October 2010 in the study area, using a multistage random sampling technique. The surveys were spread across the whole Upazila at random: one in the north (Rajapur), one in the southwest (Mokam), and the other in the middle of the Upazila (Burichong), so as to get maximum information and also to cross check the information provided by the local informants during the earlier visits. From each of the three villages, 30 households (irrespective of socioeconomic condition) were selected randomly for the comprehensive study. Thus, a total of 90 households were selected. Before the household survey, casual field visits were arranged within the villages with local old people, religious leaders, and other key informants to review and document the availability of medicinal plants in the locality. Informal meetings were held in the interviewee's home using the native language (Bengali). The household heads were the key respondents, with help from other family members when necessary. In addition, six focus group discussions (FGDs), two in each village, were arranged in the tea stalls of local market where the rural people usually get together, gossip, and interact in the evening after the daylong business. Information on the local name of plant, plant part used for curing, method of dosage, and administration was recorded. After, the interviews, collected information was cross-checked by the local herbal practitioners locally referred to as kabiraj. They had sound knowledge on medicinal plants and were therefore highly rated in the society.

Respondents were interviewed using a semistructured questionnaire and focalized interview to ascertain the plant species and the parts used, for what diseases, the sources they prefer, the reasons for cultivating any plant, and so forth. The plant species used for medicine were firstly identified by local names by the help of kabiraj and old-aged persons. The scientific names were obtained by consulting the literature $[29,30]$. A final list of the species used for medicinal purposes was cross-checked and prepared based on the study by Dey [29].

\section{Results and Discussion}

3.1. Medicinal Plants Species Composition. A total of 45 ethnomedicinal plant species including herb, shrub, tree, palm, and vine distributed across 34 families were documented in the study to be used by the rural community for curing different ailments. For the utilization frequency of the plant species, Palmae and Rutaceae appear as the most prominent families (3 species each), followed by Compositae, Cucurbitaceae, Euphorbiaceae, Labiatae, Liliaceae, Myrtaceae, and Zingiberaceae ( 2 species each) (Table 1). Various researchers across the country, for example, Leguminosae [12, 21], Compositae, Combretaceae, Leguminosae, Liliaceae, and Rutaceae [9], Fabaceae [16, 19], Euphorbiaceae and Lamiaceae [17], Convolvulaceae, Leguminosae, Solanaceae, and Sterculiaceae [22], and Fabaceae and Solanaceae [18] also recorded that the species under these families were frequently used as medicinal plants in rural Bangladesh. Among the recorded 


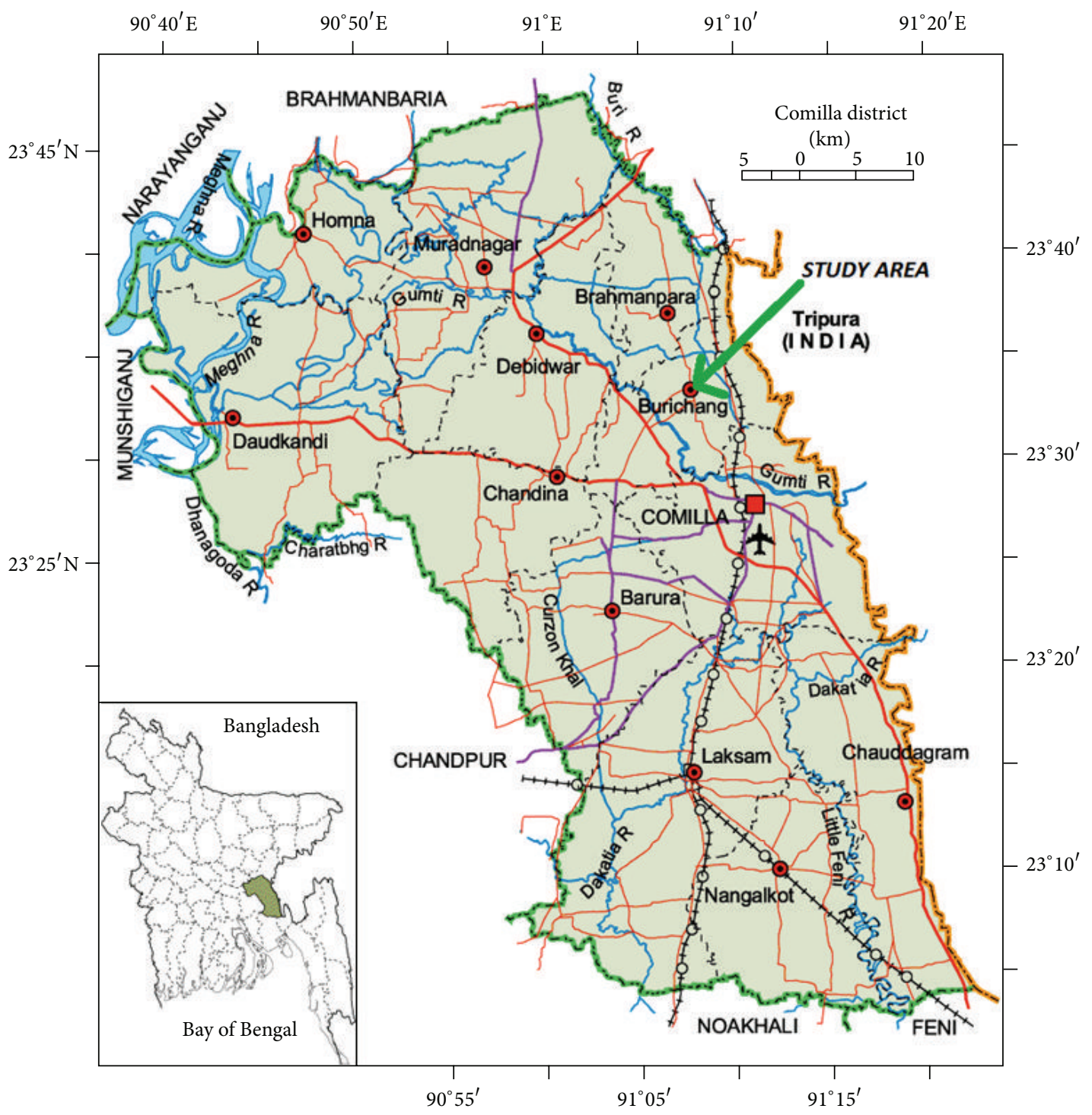

FIGURE 1: Location map of the study area.

plants, trees were the most frequent growth form $(37.78 \%)$, followed by herbs (24.44\%), shrubs $(22.22 \%)$, vine $(8.89 \%)$, and palms (6.67\%). A similar trend was also observed that trees were the most used growth form of medicinal plants in Bangladesh [2, 9, 31-36], but with a few exceptions [12, 37] where they found that herbs were mainly used as medicinal plants.

\subsection{Indigenous Ethnobotanical Knowledge, Pattern, and Ail-} ments. The survey revealed that rural people used various parts of the plants as medicine. The diverse pattern of various parts of medicinal plants (Table 1) reflected greater possession of IK regarding their health care practices by the people. Most of the medicinal plant parts are consumed after macerating, squeezing, grinding, blending, soaking, or boiling, and some are taken raw. Some are applied externally to different body parts for cuts and wounds, scabies, joint pain, piles, skin diseases, and so forth. Fifteen species like Adhatoda vasica
Nees., Artocarpus heterophyllus Lamk., Azadirachta indica A. Juss., Centella asiatica (L.) Urban, Cocos nucifera L., Lawsonia inermis L., Phoenix sylvestris Roxb., Phyllanthus emblica L., Piper betle L., Plantago ovate, Psidium guajava (L.) Bat., Ocimum sanctum L., Swertia chirata, Tamarindus indica L., and Terminalia chebula (Gaerth.) Retz. were used against up to four ailments. One unusual use of fresh mango leaf and piece of branches is as a toothbrush, without any toothpaste, to keep teeth healthy; another is the sun-dried seed of Syzygium cumini (L.) Skeel., which, after grinding into powder, is taken with salt as a regular treatment for diabetes. Another frequently used medicinal plant is the vine Momordica charantia L., where both the leaf and fruit are used against diabetes. Similarly, used patterns of these plant parts are recorded in rural areas of Bangladesh [9].

Medicinal plants are generally used to treat fever, coughs, cuts and wounds, cold ailments, toothache, hair loss, dandruff, skin diseases, joint pain, stomach problem, dysentery 


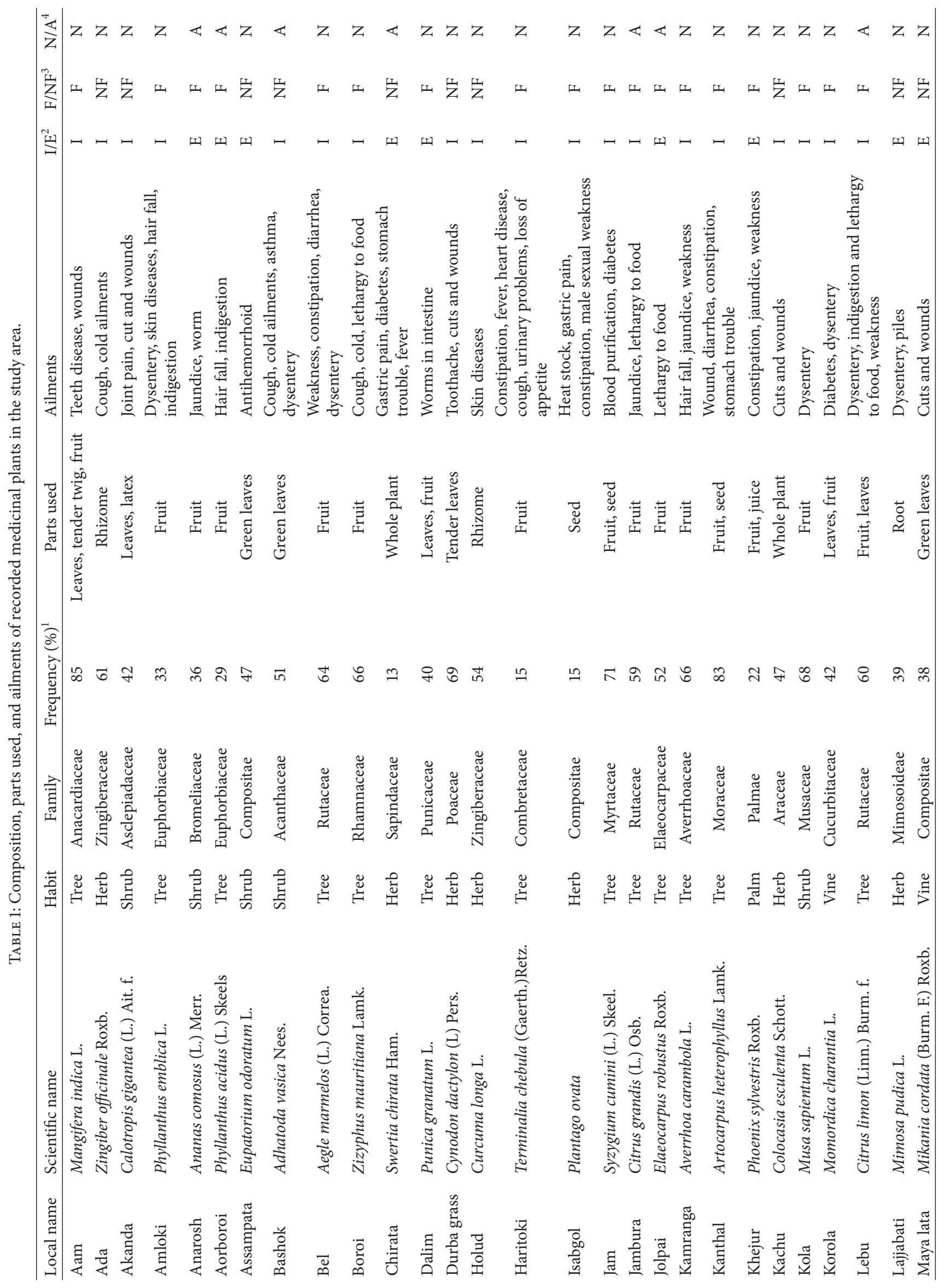




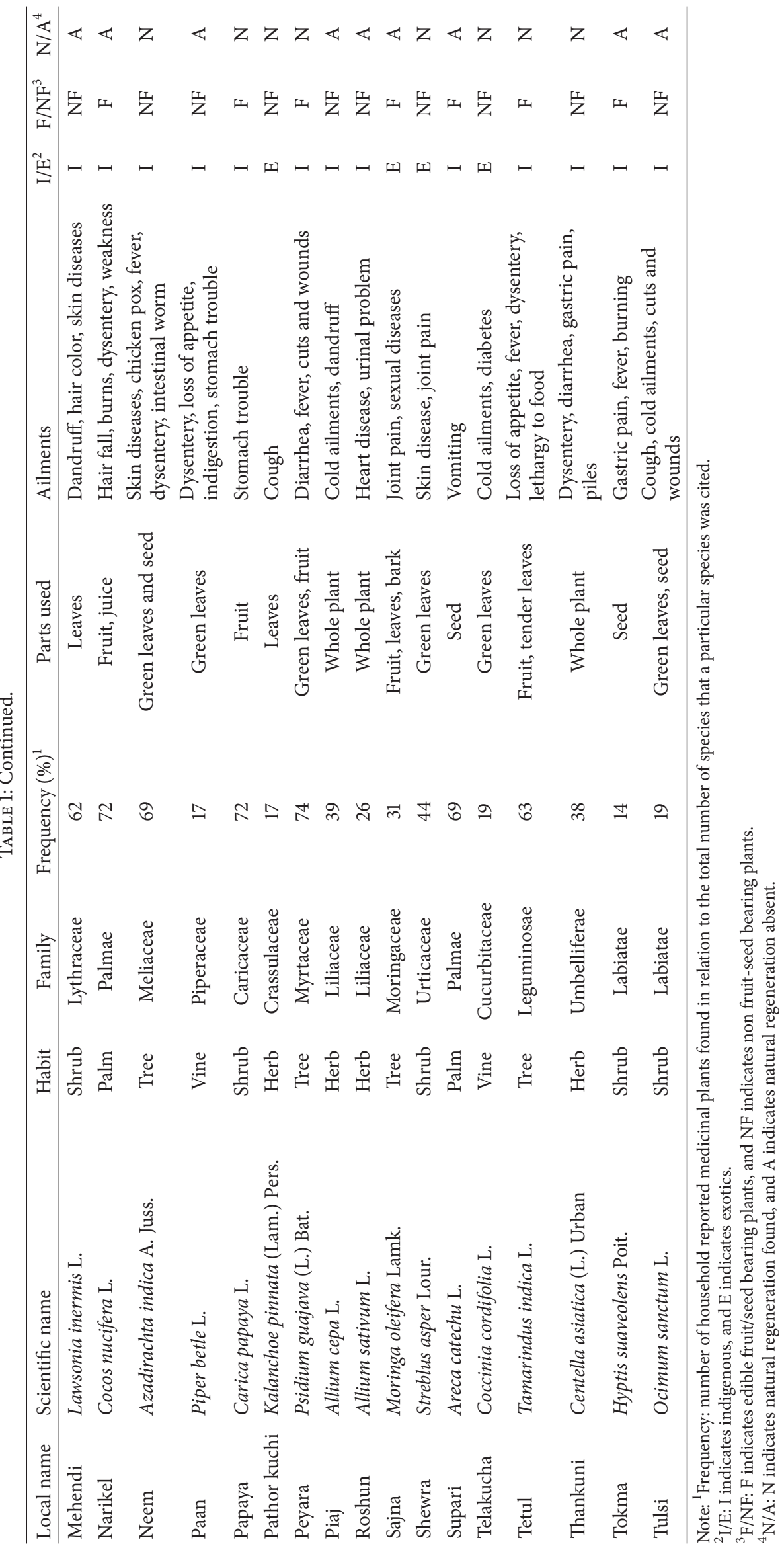


TABLE 2: Habit-wise distribution of medicinal plants for different ailments.

\begin{tabular}{|c|c|c|c|c|c|c|}
\hline \multirow{2}{*}{ Name of ailments } & \multicolumn{5}{|c|}{ Number of species reported } & \multirow{2}{*}{ Total species } \\
\hline & Tree & Herb & Shrub & Vine & Palm & \\
\hline Antihemorrhoid & - & - & 1 & - & - & $1(2.22)$ \\
\hline Asthma & - & - & 1 & - & - & $1(2.22)$ \\
\hline Blood purification & 1 & - & - & - & - & $1(2.22)$ \\
\hline Burning & - & - & 1 & - & 1 & $2(4.44)$ \\
\hline Chicken pox & 1 & - & - & - & - & $1(2.22)$ \\
\hline Cold ailments & 1 & 2 & 2 & 1 & - & $6(13.33)$ \\
\hline Constipation & 3 & 1 & - & - & 1 & $5(11.11)$ \\
\hline Cough & 2 & 2 & 2 & - & - & $6(13.33)$ \\
\hline Cuts and wounds & 1 & 1 & 2 & 1 & - & $5(11.11)$ \\
\hline Dandruff & - & 1 & 1 & - & - & $2(4.44)$ \\
\hline Diabetes & 1 & 1 & - & 2 & - & $4(8.89)$ \\
\hline Diarrhea & 3 & 1 & - & - & - & $4(8.89)$ \\
\hline Dysentery & 5 & 2 & 2 & 2 & 1 & $12(26.67)$ \\
\hline Fever & 4 & 1 & 1 & - & - & $6(13.33)$ \\
\hline Gastric pain & - & 3 & 1 & - & - & $4(8.89)$ \\
\hline Hair fall and color & 3 & - & 1 & - & 1 & $5(11.11)$ \\
\hline Heart disease & 1 & 1 & - & - & - & $2(4.44)$ \\
\hline Indigestion & 3 & - & - & 1 & - & $4(8.89)$ \\
\hline Jaundice & 2 & - & 1 & - & 1 & $4(8.89)$ \\
\hline Joint pain & 1 & - & 2 & - & - & $3(6.67)$ \\
\hline Lethargy to food & 5 & - & - & - & - & $5(11.11)$ \\
\hline Loss of appetite & 2 & - & - & 1 & - & $3(6.67)$ \\
\hline Piles & - & 2 & - & - & - & $2(4.44)$ \\
\hline Sexual problem & 1 & 1 & - & - & - & $2(4.44)$ \\
\hline Skin diseases & 2 & 1 & 2 & - & - & $5(11.11)$ \\
\hline Stomach trouble & 1 & 1 & 1 & 1 & - & $4(8.89)$ \\
\hline Toothache & 1 & 1 & - & - & 1 & $3(6.67)$ \\
\hline Urinal problem & - & 1 & - & - & - & $1(2.22)$ \\
\hline Vomiting & - & - & & - & 1 & $1(2.22)$ \\
\hline Worms & 1 & - & 1 & - & - & $2(4.44)$ \\
\hline Weakness & 2 & - & - & - & 2 & $4(8.89)$ \\
\hline
\end{tabular}

${ }^{*}$ Parenthesis shows the percentage value.

and diarrhea (Table 2). Twelve species (26.67\%) are used against dysentery (five trees, two herbs, shrubs and vine, and one palm species). Cold ailments, cough, and fever are treated with six species (13.33\%); constipation, cuts and wounds, hair fall and color, lethargy to food, and skin diseases are treated with five species (11.11\%) each. More than four species (8.89\%) are used for treating common conditions of diabetes, diarrhea, gastric pain, indigestion, jaundice, stomach trouble, and weakness. In some cases, a mixture of several species is also used for treating one disease.

For curing ailments, the use of the above ground plant parts was higher (86.44\%) than the whole plants (8.47\%) and under ground plant parts (5.08\%). Out of the above ground plant parts, fruits (37.29\%) and leaves (30.51\%) were used in the majority of cases, followed by seeds (11.86\%) (Table 3). In most cases, the juice from leaves, root, rhizome, and bark is used as medicine, while fruits are eaten raw.
TABLE 3: Utilization of plant parts of the medicinal plant species.

\begin{tabular}{lcc}
\hline Plants parts used & Individual species & Percentage \\
\hline Fruits & 22 & 37.29 \\
Leaves & 18 & 30.51 \\
Seed & 7 & 11.86 \\
Whole plant & 5 & 8.47 \\
Root/rhizome & 3 & 5.08 \\
Bark & 1 & 1.69 \\
Juice & 2 & 3.39 \\
Latex & 1 & 1.69 \\
\hline
\end{tabular}

3.3. Traditional Sources of Medicinal Plants. Home gardens in the study area are generally maintained for household consumption like supplying fruit, timber, fuel wood, and 
fodder. Additionally, due to the availability of medicinal plants in their home gardens, they are also dependent on home gardens for their daily herbal medicine. The medicine is generally prepared by elder family members who have good knowledge on the medicinal value of plants, of which those species are usually used to treat common diseases such as cough, cold ailments, and cuts and wounds, all from the plants available in the surrounding home garden, roadside, ponds and canal bank, graveyards, jungle, fallow land, hinterland, and so forth. The villagers prefer graveyards mainly covered by herbs and shrubs, to reduce the problems arising from large tree roots disturbing graves. Hinterlands behind homesteads are usually kept fallow and unproductive; in some cases, they are used for household waste disposal and as space for domestic poultry, with some herbaceous species planted. Stepp and Moerman [38] and Gazzaneo et al. [39] found a similar trend of collecting medicinal plants from anthropogenic habitats by the Maya communities of Mexico and the local herbal specialists of northeastern Brazil, respectively. A study in West Africa showed that, among the harvested species, local community used $90 \%$ of the species for medicinal purposes [40]. During the study, the respondents only buy medicinal plant parts, for example, fresh or dried forms from village markets when the species are not prevalent in their home garden. Plants, which have multiple uses, such as vegetables and spices, were cultivated in the homestead and agriculture field. Respondents also shared parts and fruits from plants with each other, so that the demands of neighbors as well as people living further away can easily be met.

3.4. Traditional Beliefs. Study found that most of the plant parts used for curing ailments are gathered from home gardens, but the people of the study area are destroying the medicinal plants resource due to lack of proper harvesting techniques and lack of awareness about this resource. Conversely, some rural people raise certain species with medicinal properties, particularly Areca catechu L., A. indica, Citrus grandis (L.) Osb., C. limon (L.) Burm. f., C. nucifera, L. inermis, and $O$. sanctum which are usually planted surrounding the homestead especially on the southern side (A. indica) that air from the south is purified by its foliage; this is believed and noticed by the local people from the study area.

Aegle marmelos (L.) Correa., A. indica, L. inermis, Mangifera indica L., O. sanctum, P. betle, Zizyphus mauritiana Lamk., and fruit of $C$. nucifera are viewed as sacred and culturally important plants by the Hindu and Muslim religious communities. The leaf of $L$. inermis $\mathrm{L}$. is often used in dyeing the hand palms of bridal couples, women and children on cultural, ceremonial, and religious occasions. While Chowdhury et al. [41] reported the livelihood potential of the commercial farming of $L$. inermis $\mathrm{L}$. in the central part of the country, Cartwright-Jones [42] noticed that $L$. inermis leaf paste is popular as an adornment for weddings and other celebrations in South Asia, the Middle East, and Africa. The orange dye obtained from the leaves is also used for dyeing hair, beards, eyebrows, fingernails, and palms.

The paste made from rhizome of the Curcuma longa L. is used in dyeing the full body of bridal couples for both communities. In the Hindu community, leaves of O. sanctum are used commonly in their worship. T. indica is planted either in the periphery of homesteads or in fallow lands of the backyard with a belief that evil spirits take shelter on its crown. Miah and Rahman [43] also reported on these plants and their cultural, ceremonial, and religious uses having positive effects on the flora of the Muslim and Hindu homestead forests in Bangladesh. In the study area, more than half of the medicinal plants (tree species) are being edible fruit bearers as they are planted purposively by the local people for the seasonal fruit not for the medicinal purposes.

\subsection{Ethnobotanical Knowledge Regarding Biodiversity Con-} servation. Home gardens have long been the most effective and widespread measure for biodiversity conservation in Bangladesh due to anthropogenic pressure and land-use change affecting the natural forest which has been decreasing day by day both in explicit and implicit ways leading to threats to future productivity. Among the identified species, about $71.11 \%$ of plants are indigenous species, and $28.89 \%$ of plants are exotic species. To get a quick cash return now, the largest part of home garden owners are interested in the plantation of exotic plant species although it has a negative effect on biodiversity. It was found that $48.89 \%$ of plants produce edible fruits and seeds, $28.89 \%$ of the plants parts are used as vegetables and spices for daily cooking purposes by the people. Generally, rural communities preferred cultivated and planted multipurpose species that can be served as fruits, vegetables and spices that also can be used as timber. Such kind of choice is the most important factor to home gardens conservation in Bangladesh. This clearly plays a significant role in forest biodiversity conservation since all the wood and other nontimber products that are harvested in the home gardens do not need to be collected from natural forests. Some species (e.g., P. ovate, Kalanchoe pinnata (Lam.) Pers., Hyptis suaveolens Poit., and O. sanctum L.) are grown in earthen pots and kept in front of dwelling houses, serving for beautification purposes. About $57.78 \%$ of plants are suitable for animals' and birds' conservation because the fruits and seeds of these plants are widely used as food for birds and animals. At this time, dispersal of seeds also occurs and helps in natural regeneration of plants species. In the present study, $64.44 \%$ of species are found to be naturally regenerated, and most of these are indigenous (Table 4).

The conservation of plants in home gardens not only preserves a vital resource for humankind but also provides significant economic and nutritional benefits for the rural poor [44]. During the study, it was found that collecting and selling the whole plant of Allium cepa L., Allium sativum L., C. asiatica, Colacasia esculenta Schott., and S. chirata; the fruit of M. indica, Phyllanthus emblica L., Aannas comosus (L.) Merr., Phyllanthus acidus (L.) Skiels, A. marmelos, Z. mauritiana, Punica granatum L., T. chebula, S. cumini, C. grandis, Elaeocarpus robustus Roxb., Averrhoa carambola L., A. heterophyllus, P. sylvestris, Musa sapientum L., C. limon, M. charantea, C. nucifera, Carica papaya L., P. guajava, and T. indica; the leaves with rhizome of C. esculenta and Zingiber officinale Roxb.; moreover the seeds of P. ovate, A. heterophyllus, A. catechu, $H$. suaveolens Poit., and $O$. sanctum play a significant role in household's cash income generation as well 
TABLE 4: Status of medicinal plants species from biodiversity conservation point of view.

\begin{tabular}{lcc}
\hline Species category & $\begin{array}{c}\text { Individual } \\
\text { species }\end{array}$ & Percentage \\
\hline Indigenous & 32 & 71.11 \\
Exotics & 13 & 28.89 \\
Plants produce edible fruits/seeds & 22 & 48.89 \\
Plants parts used as spices/vegetables & 13 & 28.89 \\
Plants parts suitable for animals and birds & 26 & 57.78 \\
Natural regeneration present & 29 & 64.44 \\
Natural regeneration absent & 16 & 35.56 \\
\hline
\end{tabular}

as meet the body requirement of vitamins. Such economic contribution of these species also has a significant role in species conservation and poverty reduction in the study area. Several studies [40, 45-48] found that medicinal plants play a key role in sustaining the rural livelihood and contributing to poverty reduction.

3.6. Traditional Management System. In terms of the level of management in cultural practices, traditional production system of home gardens in Bangladesh is very poor. Owners mainly depend on naturally growing trees on the home gardens. However, both men and women play a significant role in decision making in case of choice of species, nursery raising, plantation, silvicultural practices, and management activities of medicinal plants. Mostly women encouraged both their neighbors and family to conserve home gardens by planting diverse plant species especially medicinal plants and by taking proper care of the gardens. It was found that laborintensive activities like digging holes (78\%), pruning (63\%), planting species (66\%), and fencing (59\%) were done by men, while seed selection $(74 \%)$, watering (79\%), fertilizing (52\%), and weeding (51\%), utilization patterns of medicinal plants $(60 \%)$, and storage and pest control techniques (67\%) were mainly done by women.

Families exchange seeds of medicinal plants among themselves, usually at the time of fruit selection. Cattle browsing, pest and disease attack, low productivity, and poor fertility of seeds with sometimes-human disturbance are common problems expressed by the owner. Women also have a responsibility for pest control and use a simple indigenous technique to pest control in their garden which is the application of ashes to plants infected by pests. For excessive pest and disease attacks, they used pesticide but at a low rate that could not affect human and animals. Recently, majority of the households were interested to know about species suitability, appropriate mixture, and information related to high yielding and more pest-disease resistance varieties. Cultivation of medicinal plants species is an important strategy for conservation and sustainable maintenance of home gardens. However, the home gardens present an outstanding example of all acceptance multipurpose land-use system and biodiversity conservation point of view.

\section{Conclusion}

This study revealed that there are medicinal plants species that make a significant contribution to the healing of diseases of rural community. Due to the increased dependence on herbal treatment and overexploitation of plants, not only by the Kabiraj, but also by most of the local people, anthropogenic pressures on medicinal plants are more increased. From the conservation point of view, the plants diversity is critically depleted due to habitat destruction. Therefore, there is an urgent need for conservation of the genetic diversity of the species with special emphasis on anthropogenic populations. Further work should focus on the thorough phytochemical investigation such as alkaloid extraction and isolation along with few clinical trials. This could help in creating mass awareness regarding the need for conservation of such plants and in promoting ethno-medico-botany knowledge within the region. Besides, the young generation should be motivated to acquire this traditional medicinal knowledge. Both government agencies and nongovernmental organizations have roles to play in this regard. This also contributes to the preservation and enrichment of the gene bank of such economically important species before they are lost forever. While there is an issue on the conservation of biological diversity all over the world, local people are using plants for their health care in a sustainable manner, and this may be the key factor in the conservation of plant diversity. It can be concluded from the study that people inherit a rich traditional knowledge and documentation of this knowledge has provided novel information from the area.

\section{References}

[1] S. Lee, C. Xiao, and S. Pei, "Ethnobotanical survey of medicinal plants at periodic markets of Honghe Prefecture in Yunnan Province, SW China," Journal of Ethnopharmacology, vol. 117, no. 2, pp. 362-377, 2008.

[2] S. A. Mukul, M. B. Uddin, and M. R. Tito, "Medicinal plant diversity and local healthcare among the people living in and around a conservation area of Northern Bangladesh," International Journal of Forest Usufructs Management, vol. 8, no. 2, pp. 50-63, 2007.

[3] S. Elliot and J. Brimacombe, The Medicinal Plants of Gunung Leuser National Park, Indonesia, WWF, Gland, Switzerland, 1986.

[4] H. Yineger, E. Kelbessa T Bekele, and E. Lulekal, "Plants used in traditional management of human ailments as Bale Mountains National Park, Southeastern Ethiopia," Journal of Medicinal Plants Research, vol. 2, pp. 132-153, 2008.

[5] Z. U. Ahmed, Z. N. T. Begum, M. A. Hassan et al., Encyclopedia of Flora and Fauna of Bangladesh: Index Volume-Flora, vol. 13, Asiatic Society of Bangladesh, Dhaka, Bangladesh, 1st edition, 2009.

[6] A. Ghani, Medicinal Plants of Bangladesh With Chemical Constituents and Uses, Asiatic Society of Bangladesh, Dhaka, Bangladesh, 2003.

[7] M. M. Haque, "Inventory and documentation of medicinal plants in Bangladesh," in Medicinal Plants Research in Asia: the Framework and Project Work Plans, P. A. Batugal, J. Kanniah, L. S. Young, and J. T. Oliver, Eds., vol. 1, pp. 45-47, International 
Plant Genetic Resources Institute-Regional Office for Asia, the Pacific and Oceania, Serdang, Selangor DE, Malaysia, 2004.

[8] FAO, State of the World's forests 2009, Food and Agriculture Organization of the United Nations, Rome, Italy, 2010.

[9] M. S. H. Chowdhury, M. Koike, N. Muhammed, M. A. Halim, N. Saha, and H. Kobayashi, "Use of plants in healthcare: a traditional ethno-medicinal practice in rural areas of southeastern Bangladesh," International Journal of Biodiversity Science and Management, vol. 5, no. 1, pp. 41-51, 2009.

[10] A. Z. M. M. Rashid, Rare and endangered economic plants of Bangladesh, 2008, http://www.fao.org/DOCREP/004/Y3660e/ y3660e05.htm.

[11] N. T. Vergara, "Indigenous knowledge and biodiversity conservation in forestry," in Proceedings of The National Workshop on Local Knowledge and Biodiversity Conservation in Forestry Practice and Education, Visayas State University, Visca, Philippines, October 1998.

[12] M. Abdul Halim, M. S. H. Chowdhury, A. I. Wadud, M. S. Uddin, S. K. Sarker, and M. B. Uddin, "The use of plants in traditional health care practice of the shaiji community in Southwestern Bangladesh," Journal of Tropical Forest Science, vol. 19, no. 3, pp. 168-175, 2007.

[13] M. Thomsen, S. Halder, and F. U. Ahmed, Medicinal and Aromatic Plant Industry Development, InterCooperation, Dhaka, Bangladesh, 2005.

[14] F. U. Ahmed, Production, Processing and Marketing of Medicinal Plant in Bangladesh, Aranyak Foundation, Dhaka, Bangladesh, 2009.

[15] M. Hossain, Bangladesh Seeks Global Market For Its Medicinal Plants, Science and Development Network, Dhaka, Bangladesh, 2005.

[16] M. Rahmatullah, A. H. Mollik, M. Ali et al., "An ethnomedicinal survey of Vitbilia village in sujanagar sub-district of pabna district, Bangladesh," The American-Eurasian Journal of Agriculture and Environmental Science, vol. 10, no. 1, pp. 106-111, 2011.

[17] M. M. Hasan, E. A. Annay, M. Sintaha et al., "A survey of medicinal plant usage by folk medicinal practitioners in seven villages of Ishwardi Upazilla, Pabna District, Bangladesh," The American-Eurasian Journal of Sustainable Agriculture, vol. 4, no. 3, pp. 326-333, 2010 .

[18] M. Rahmatullah, M. A. Khatun, N. Morshed et al., "A randomized survey of medicinal plants used by folk medicinal healers of Sylhet division, Bangladesh," Advances in Natural and Applied Sciences, vol. 4, no. 1, pp. 52-62, 2010.

[19] M. Rahmatullah, M. A. H. Mollik, M. A. Jilani et al., "Medicinal plants used by folk medicinal practitioners in three villages of natore and Rajshahi districts, Bangladesh," Advances in Natural and Applied Sciences, vol. 4, no. 2, pp. 132-138, 2010.

[20] M. Rahmatullah, D. Ferdausi, M. A. H. Mollik, R. Jahan, M. H. Chowdhury, and W. M. Haque, "A survey of medicinal plants used by Kavirajes of Chalna area, Khulna district, Bangladesh," African Journal of Traditional, Complementary and Alternative Medicines, vol. 7, no. 2, pp. 91-97, 2010.

[21] A. H. Md. Mahabub Nawaz, M. Hossain, M. Karim, M. Khan, R. Jahan, and M. Rahmatullah, "An ethnobotanical survey of Rajshahi district in Rajshahi division, Bangladesh," The American-Eurasian Journal of Sustainable Agriculture, vol. 3, no. 2, pp. 143-150, 2009.

[22] A. H. Md. Mahabub Nawaz, M. Hossain, M. Karim, M. Khan, R. Jahan, and M. Rahmatullah, "An ethnobotanical survey of
Jessore district in Khulna division, Bangladesh," The AmericanEurasian Journal of Sustainable Agriculture, vol. 3, no. 2, pp. 195201, 2009.

[23] M. Rahmatullah, D. Ferdausi, A. H. Mollik, N. K. Azam, M. Taufiq-Ur-Rahman, and R. Jahan, "Ethnomedicinal survey of bheramara area in Kushtia district, Bangladesh," The AmericanEurasian Journal of Sustainable Agriculture, vol. 3, no. 3, pp. 534541, 2009.

[24] M. Rahmatullah, A. Noman, M. S. Hossan et al., "A survey of medicinal plants in two areas of Dinajpur district, Bangladesh including plants which can be used as functional foods," The American-Eurasian Journal of Sustainable Agriculture, vol. 3, no. 4, pp. 862-876, 2009.

[25] M. Rahmatullah, A. K. Das, M. A. H. Mollik et al., "An ethnomedicinal survey of Dhamrai sub-district in Dhaka district, Bangladesh," The American-Eurasian Journal of Sustainable Agriculture, vol. 3, no. 4, pp. 881-888, 2009.

[26] M. Yusuf, M. A. Wahab, J. U. Choudhury, and J. Begum, "Ethno-medico-botanical knowledge from Kaulkhali proper and Betunia of Rangamati district," Bangladesh Journal of Plant Taxonomy, vol. 13, no. 1, pp. 55-61, 2006.

[27] S. N. Uddin, M. Z. Uddin, M. A. Hassan, and M. M. Rahman, "Preliminary ethnomedical plant survey in Khagrachari district, Bangladesh," Bangladesh Journal of Plant Taxonomy, vol. 11, no. 2, pp. 39-48, 2004.

[28] “Banglapedia: National Encyclopedia of Bangladesh," Burichong Upazila, 2006, http://www.banglapedia.org/HT/B_0659.HTM.

[29] T. K. Dey, Useful Plants of Bangladesh, The Ad Communication, Chittagong, Bangladesh, 2nd edition, 2006.

[30] K. D. Das and M. K. Alam, Trees of Bangladesh, Bangladesh Forest Research Institute, Chittagong, Bangladesh, 2001.

[31] M. D. Miah and M. S. H. Chowdhury, "Indigenous healthcare practice through medicinal plants from forest by the Mro tribe in Bandarban region, Bangladesh," INDILINGA: African Journal of Indigenous Knowledge System, vol. 2, pp. 61-73, 2003.

[32] M. A. S. A. Khana, S. Ahmed Mukul, M. Salim Uddin, M. Golam Kibria, and F. Sultana, "The use of medicinal plants in healthcare practices by Rohingya refugees in a degraded forest and conservation area of Bangladesh," International Journal of Biodiversity Science and Management, vol. 5, no. 2, pp. 76-82, 2009.

[33] M. S. H. Chowdhury and M. Koike, “Therapeutic use of plants by local communities in and around Rema-Kalenga Wildlife Sanctuary: implications for protected area management in Bangladesh," Agroforestry Systems, vol. 80, no. 2, pp. 241-257, 2010.

[34] M. H. Rahman, M. J. Fardusi, and M. S. Reza, "Traditional knowledge and use of medicinal plants by the Patra tribe community in the North-Eastern region of Bangladesh," Proceedings of the Pakistan Academy of Sciences, vol. 48, no. 3, pp. 159-167, 2011.

[35] H. Rahman, M. Rahman, M. Islam, and S. Reza, "The importance of forests to protect medicinal plants: a case study of Khadimnagar National Park, Bangladesh," International Journal of Biodiversity Science, Ecosystems Services and Management, vol. 7, no. 4, pp. 283-294, 2011.

[36] M. H. Rahman, M. Rahman, B. Roy, and M. J. Fardusi, "Topographical distribution, status and traditional uses of medicinal plants in a tropical forest ecosystem of Northeastern Bangladesh," International Journal of Forest Usufructs Management, vol. 12, no. 1, pp. 37-56, 2011. 
[37] M. A. S. A. Khan, F. Sultana, M. H. Rahman, B. Roy, and S. I. Anik, "Status and ethno-medicinal usage of invasive plants in traditional health care practices: a case study from northeastern Bangladesh," Journal of Forestry Research, vol. 22, no. 4, pp. 649658, 2011.

[38] J. R. Stepp and D. E. Moerman, "The importance of weeds in ethnopharmacology," Journal of Ethnopharmacology, vol. 75, no. 1, pp. 19-23, 2001.

[39] L. R. S. Gazzaneo, R. F. Paiva de Lucena, and U. P. de Albuquerque, "Knowledge and use of medicinal plants by local specialists in an region of Atlantic Forest in the state of Pernambuco (Northeastern Brazil)," Journal of Ethnobiology and Ethnomedicine, vol. 1, article 9, 2005.

[40] S. Paré, P. Savadogo, M. Tigabu, J. M. Ouadba, and P. C. Odén, "Consumptive values and local perception of dry forest decline in Burkina Faso, West Africa," Environment, Development and Sustainability, vol. 12, no. 2, pp. 277-295, 2010.

[41] M. S. H. Chowdhury, M. M. Rahman, M. Koike et al., "SmallScale Mehedi (Lawsonia inermis L.) farming in the central Bangladesh: a promising NTFP-based rural livelihood outside the forests," Small-Scale Forestry, vol. 9, no. 1, pp. 93-105, 2010.

[42] C. Cartwright-Jones, Developing Guidelines on Henna: A geographical Approach, TapDancing Lizard Publishing, 2006.

[43] M. D. Miah and M. M. Rahman, "The effect of religious subculture on the stock and diversity of the village forests in the flood-plain area of Bangladesh," in Proceedings of The Human Dimensions of Family, Farm, and Community Forestry International Symposium, pp. 89-94, Washington State University, Pullman, Wash, USA, Mar2004.

[44] B. M. Kumar and P. K. R. Nair, Tropical Homegardens: A TimeTested Example of Sustainable Agroforestry, Springer, Amsterdam, The Netherlands, 2006.

[45] P. Parveen, B. Upadhyay, S. Roy, and A. Kumar, “Traditional uses of medicinal plants among the rural communities of Churu district in the Thar Desert, India," Journal of Ethnopharmacology, vol. 113, no. 3, pp. 387-399, 2007.

[46] P. M. Shrestha and S. S. Dhillion, "Medicinal plant diversity and use in the highlands of Dolakha district, Nepal," Journal of Ethnopharmacology, vol. 86, no. 1, pp. 81-96, 2003.

[47] J. Okello and P. Ssegawa, "Medicinal plants used by communities of Ngai Subcounty, Apac District, northern Ugand," African Journal of Ecology, vol. 45, no. 1, pp. 76-83, 2007.

[48] P. Ssegawa and J. M. Kasenene, "Medicinal plant diversity and uses in the Sango bay area, Southern Uganda," Journal of Ethnopharmacology, vol. 113, no. 3, pp. 521-540, 2007. 

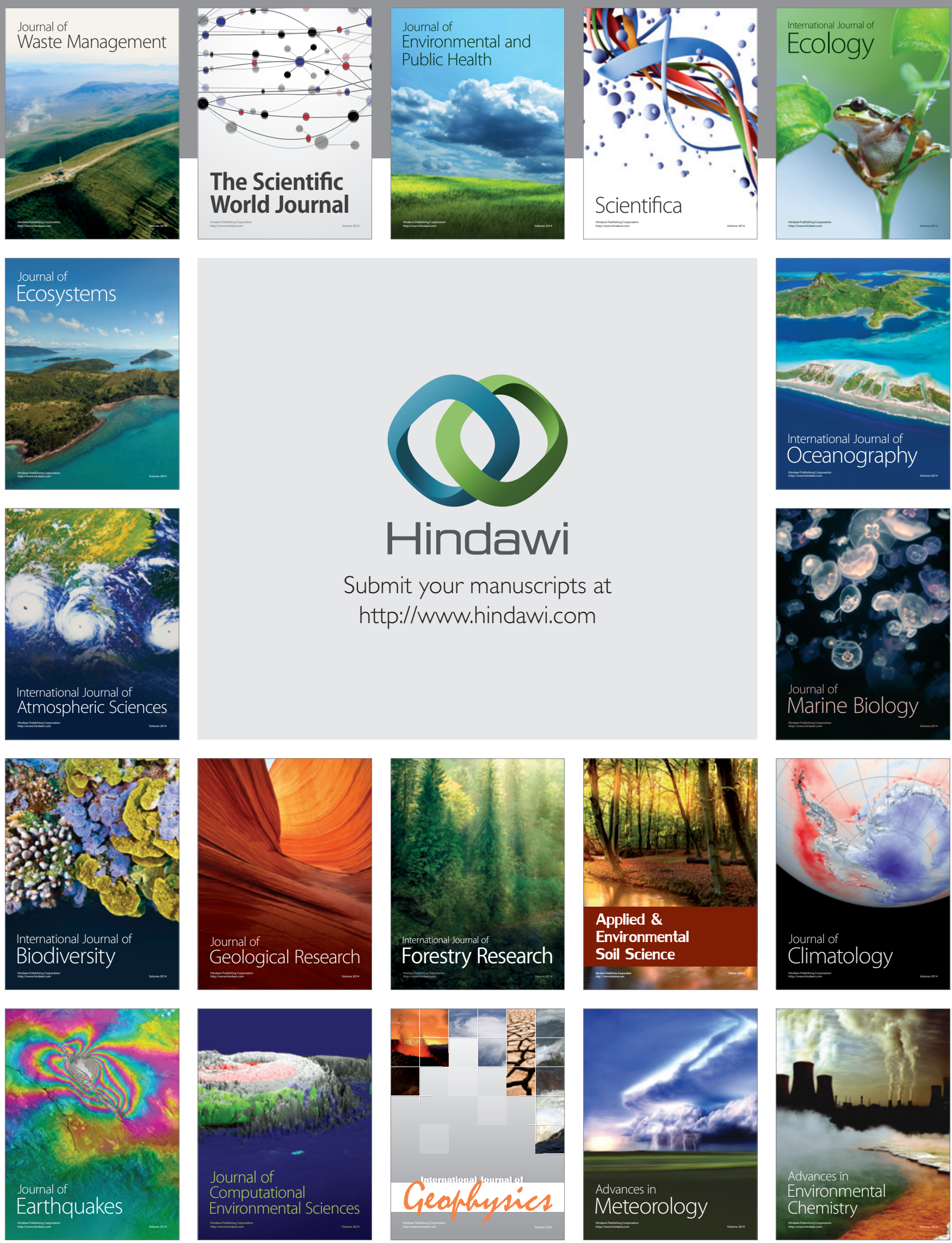